\title{
MUTATIONS IN THE RPOB GENE OF MYCOBACTERIUM TUBERCULOSIS IDENTIFIED BY SEQUENCING METHOD
}

\author{
SURESH BABU R ${ }^{1,2}$, LAKSHMI MURALI ${ }^{2}$, PALANISWAMY M $^{1 *}$ \\ ${ }^{1}$ Department of Microbiology, Karpagam University, Coimbatore, Tamil Nadu, India. ${ }^{2}$ State Tuberculosis Training and Demonstration \\ Centre/Intermediate Reference Laboratory, ITM Campus, TB Hospital, Chennai, Tamil Nadu, India. Email: m.palaniswamy@gmail.com
}

Received: 26 November 2016, Revised and Accepted: 06 December 2016

\section{ABSTRACT}

Objective: To identify the mutation in the rpoB gene of Mycobacterium tuberculosis (MTB), using by sequencing method from pulmonary specimens of presumptive TB patients belonging to the districts of Tamil Nadu.

Methods: A total of 8697 clinical specimens of presumptive MTB patients were collected from various districts of Tamil Nadu. Smear microscopy was performed by light emitting diode fluorescent microscopy and all the smear positive samples were tested using line probe assay (LPA) to detect the percentage of drug resistance pattern and to identify the missing mutation in LPA by the sequencing method.

Results: Among 4897 smear positives subjected to LPA method; 407 (8.3\%) MTB was not detected and 16 (0.3\%) showed invalid result; 4473 (91.4\%) strains showed MTB positive; 3695 (82.6\%) were sensitive for both rifampicin (RIF) and isoniazid (INH) drugs; 502 (11.2\%) were resistance for INH; 73 (1.6\%) resistant for RIF; 203 (4.5\%) were resistance for RIF and INH. Totally, 52 (1.2\%) strains results cannot be confirmed by LPA and reported as sensitive for RIF, because of the faint and the missing bands in both wild type and mutation. These strains were sequenced and 39 (75\%) strains showed resistant to RIF

Conclusion: Hence LPA may be the molecular technology for the rapid, feasible and reliable method for the detection of multidrug resistant mutation but few confusion bands cannot be reported as resistance, which should be confirmed by either conventional phenotypic drug susceptibility testing or by sequencing method.

Keywords: Line probe assay, Sequencing, Mutation, Multidrug resistant tuberculosis.

(c) 2017 The Authors. Published by Innovare Academic Sciences Pvt Ltd. This is an open access article under the CC BY license (http://creativecommons. org/licenses/by/4. 0/) DOI: http://dx.doi.org/10.22159/ajpcr.2017.v10i3.16348

\section{INTRODUCTION}

In 2013, more than 9 million people fell ill with tuberculosis (TB) and 4,80,000 people developed multidrug-resistant TB (MDR-TB) globally and there were an estimated 2,10,000 deaths from MDR-TB [1]. In worldwide, the TB disease remains the most dangerous infectious diseases. Providing treatment and control of TB is more complicated due to emergence of drug resistant even MDR strains, MDR-TB can be defined as resistant to both isoniazid (INH) and rifampin (RIF) with or without other anti-TB drugs [2]. Around 500 new smear-positive MDRTB cases were estimated to occur per year in the country [3].

Conventional culture and drug susceptibility testing (C \& DST) by solid or liquid is a slow process which may take 2-4 months, during this time a patient is often treated according to the standard regimen for drug-susceptible TB. This results delay in proper treatment, adversely affect the outcome of the treatment and transmission of the drug resistant TB [4]. The financial, infrastructural and human resource requirements, widespread implementation of culture-based DST is challenging in such settings. The specimen transport and the specimen contamination issues may also present further challenges [5], hence early diagnosis of TB and rapid detection of RIF resistance is important for proper management of drug-resistant TB [6]. Even though major efforts are being taken and implemented by the government to increase case detection, one-third of new TB cases are still missed due to nonavailability of rapid, low-cost, and accurate diagnostic facilities in high-TB-burden countries like India. Over the last many years, efforts were taken to improve and develop rapid diagnostic tools for diagnosis and DST of TB. The World Health Organization (WHO) issued 10 policy statements for improving diagnosis of $\mathrm{TB}$, including the use of commercial and noncommercial DST methods and implementation of molecular methods such as the line probe assay (LPA) and Xpert Mycobacterium TB (MTB)/RIF assay [7].

In INH-resistant strains, the most common mutations were occurred in either the gene (katG) encoding catalase-peroxidase, which is required for the activation of prodrug $\mathrm{INH}$, or in the promoter region of the inhA, encoding enoyl-acyl reductase, which is involved in Mycobacterium cell wall biosynthesis [8,9]. RIF resistance strains were serve as a surrogate marker for MDR-TB detection because 96\% RIF-resistant strains are also resistant to INH [10]. Resistance in RIF was attributed to mutations within an 81-bp RIF resistancedetermining region (RRDR) of the rpoB gene, corresponding to codons $507-533$ in $96 \%$ of RIF resistance strains [11,12]. Mutations outside of RRDR were also reported with a frequency of $<2 \%$ [13]. More than 50 mutations were characterized within this region by deoxyribonucleic acid (DNA) sequencing but only point mutations at codons 526 or 531 are known to cause high levels of RIF resistance [14]. In contrast, mutations in codons 511,516, 518, 522, and 533 cause low-level resistance to RIF. Mutations conferring RIF resistance occur rarely in other regions of the $r p o B$ gene [15]. Of the two recently introduced molecular diagnostic methods for RIF resistance detection, LPA technology is based on reverse hybridization of DNA on the strip, when the Xpert MTB/RIF assay is based on real-time polymerase chain reaction (PCR). The strip-based DNA hybridization, i.e., the genotype MTBDRplus (Hain LifeScience, Nehren, Germany) referred as to LPA. Both LPA and Xpert MTB/RIF assays show good performance ( $98 \%$ sensitivity) for RIF resistance detection when compared with the gold standard phenotypic DST. As per the WHO guidelines, the standard turnaround time for reporting the LPA results is 2-3 days, 
depending on the timings of sample receiving and reporting of the result. It is mainly advocated for using with smear-positive samples. Where its sensitivity is reported to be $98 \%$. In smear-negative/ culture-positive samples its detection rate is low (72.5-76.9\%) [16], though its accuracy may vary from region to region due to variation in the circulating MTB strains [17]. Recently, the WHO recommended the use of molecular LPAs for rapid screening of MDR-TB in low and middle income settings [18]. These new assays were developed to detect resistance faster using genotype, rather than phenotype. The GenoType ${ }^{\circledR}$ MTBDRplus test is a DNA strip assay which uses multiplex PCR and amplification and reverse hybridization to identify MTB complex and mutations to detect mutations in the inhA, katG, and genes rpoB genes that confer RIF and INH resistance [19].

LPAs use PCR, LPA is performed directly from acid-fast bacilli (AFB) smear-positive sputum, or from culture isolates, and provide results in 1-2 days. A recent systematic review concludes that LPA are highly sensitive and specific for the detection of RIF resistance $(\geq 97 \%$ and $\geq 99 \%$ ) and INH resistance ( $\geq 90 \%$ and $\geq 99 \%$ ) on culture isolates and smear-positive sputum. Overall agreement with conventional DST for detection of MDR-TB was 99\% [20].

\section{METHODS}

\section{Ethics and settings}

This laboratory is accredited as an Intermediate Reference Laboratory (IRL) for LPA testing by Revised National TB Control Programme (RNTCP), India, and certified by the National Reference Laboratory (NRL), National Institute of Research in TB, Chennai. Since the observations were made as a part of national TB control program, a separate ethics clearance was not required [21].

\section{Specimens and the study population}

A total of 8697 specimens of presumptive MDR-TB cases were received for C \& DST from the district TB center (DTC) of Tamil Nadu from January to December 2015. These specimens were collected and packed with ice gel pack and transported through courier as per standard operating procedure from DTC's to the laboratory. The smear microscopy was performed by fluorescent microscopy method (Auromine-0)-light emitting diode FM [22]. Based on smear microscopy results, the smear positive specimens 4897 were subjected to LPA genotypic method. The GenoType ${ }^{\circledR}$ MTBDRplus assay (LPA) (Hain LifeScience GmbH, Nehren, Germany) was carried out according to the manufacturer's instructions [23].

\section{Laboratory work-up of sputum specimens \\ Sample processing}

All sputum samples were processed using the $N$-acetyl-L-cysteinesodium citrate- $\mathrm{NaOH}$ method and neutralized with phosphate buffer solution $\mathrm{pH}$ 6.8. [24]. Samples were decontaminated by the following centrifugation, and these sediments were resuspended for $2 \mathrm{ml}$ of phosphate buffer solution. Aliquots were prepared from the processed sample per quantity of the original sample.

\section{$L P A$}

The LPA was performed according to the manufacturer's protocol [25]. The test is based on DNA strip technology and has three steps: DNA extraction, multiplex PCR amplification, and reverse hybridization (Fig. 1), all the three steps were performed as per the WHO recommendations as follows (Fig. 2) [26].

\section{DNA extraction}

The LPA diagnostic technique is based on the PCR amplification of specific regions of DNA. DNA must, therefore, be extracted from the specimen under investigation to make a genotypic diagnosis of the drug susceptibility pattern. The extraction of the DNA from the AFB in the specimen is done by chemical denaturation after the partial cell lyses during the heat-killing step.

\section{DNA amplification}

Target DNA was amplified and it is the template to the amplification. Primers (short oligonucleotides of between 18 and 26 base pairs) that will recognize their corresponding sequence on the single stranded DNA and initiate the reaction, and the DNA precursors (the four deoxynucleoside triphosphates, dATP, dCTP, dGTP, and dTTP) these are used as building blocks for the elongation of the single stranded DNA. A thermo stable Thermus aquaticus DNA polymerase (Hot Start Taq) which will elongate the DNA molecule by facilitating the incorporation of the free nucleotides onto the end of the primer, according to the complementary base on the single stranded target DNA.

These reactions are fundamental in ensuring that sufficient DNA is amplified and will be easily detected in the hybridization process, after 30 cycles of amplification, the DNA products will be in the order of $2^{30}$, with sufficient product to be easily visualized as a distinct band when bound to probes on the LPA strip.

\section{Hybridization}

Hybridization was performed by automated GT blot 48. This chemical denaturation of the amplified products were hybridization of the single-stranded-biotin-labeled amplicons to membrane-bound probes and stringent washing of the nonspecifically bound amplicons with the addition of a streptavidin/alkaline phosphatase (AP) conjugate. The banding patterns are produced when the substrate (hydrogen peroxide) reacts with the AP, these turns and visualized the bound amplicons purplish-brown (Fig. 3) [27]

\section{Sequencing}

Few strains results cannot be confirmed by LPA and reported as sensitive for RIF, because of the faint and the missing bands in both wild type and mutation. These strains were sequenced to identify the changes in the amino acid sequence and mutations were detected in $r p o B$ gene of MTB for RIF resistance.

\section{RESULTS}

A total of 4896 AFB smear positive pulmonary specimens were tested with LPA method. Out of 4896 samples 407 (8.3\%) samples were MTB not detected and $16(0.3 \%)$ invalid results on the LPA. Of the remaining 4473 samples, $3695(82.6 \%)$ were susceptible for the both RIF and INH, 203 (4.5\%) had MDR, 502 (11.2\%) showed INH mono resistance, and $73(1.6 \%)$ shows RIF mono resistance as shown in Table 1. Among 4473 MTB detected by LPA method, $52(1.2 \%)$ were reported as sensitive with the faint and missing band in WT8 and also in MUT 3 but, out of these 52 specimens, 39 (75\%) specimens showed resistant by sequencing method Tables 1 and 2 .

\section{DISCUSSION}

Rapid diagnosis for the resistant associated with the drug resistant strains due to the mutation is a major challenge for the successful treatment of the drug resistance TB. At present available methods such has LPA method (GenoType MTBDRplus), which offers limited detection capabilities, particularly when novel or uncommon amino acid substitutions and in the silent mutation due to changes within the known drug resistance regions or even in the undiscovered amino acid mutation impact drug resistance [28]. Hence, the sequence for doubtful and the faint bands strains to identify the changes or the mutations in the genes to diagnose the drug resistance TB even rapidly are done in this study.

In this study, the drug resistant $\mathrm{TB}$ is about $273(6.2 \%)$, this is comparatively less than other study of $2.3 \%$ [29], LPAs are currently validated only for using directly from smear-positive specimens, although the reasonable performance in a small sample of smearnegative specimens was demonstrated by Barnard and Somoskovi. Although smear-positive TB cases are the most infectious [30], as part of its role in the development and evaluation process of new diagnostic 


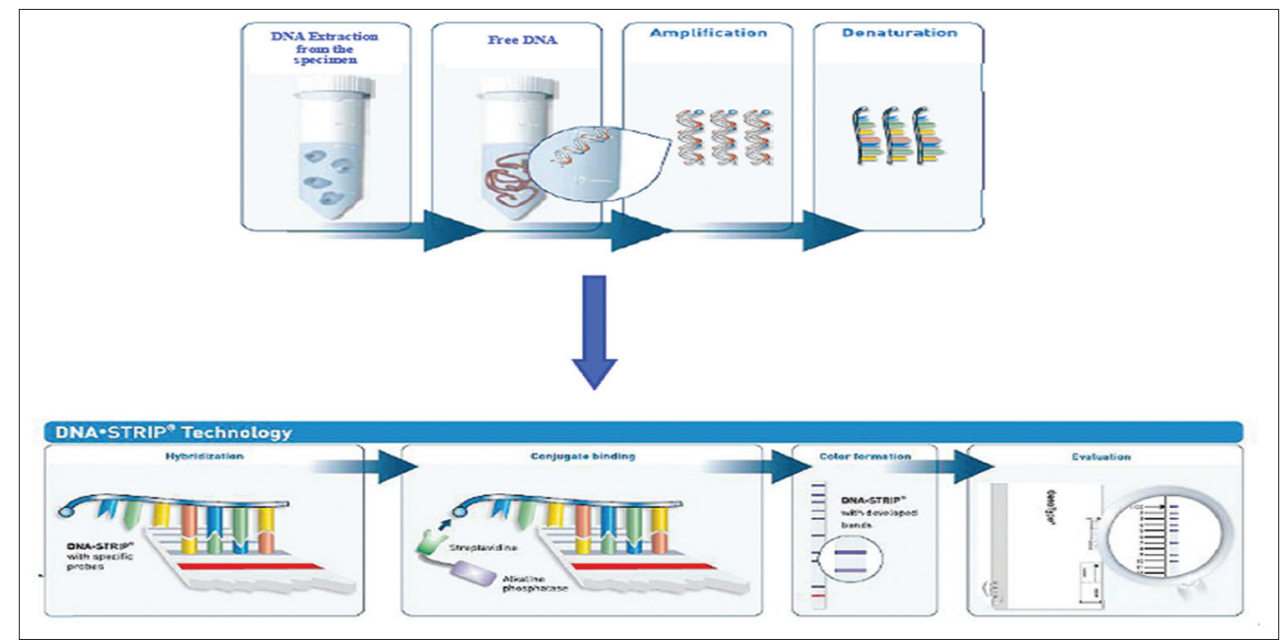

Fig. 1: Illustration of the DNA-strip technology by Hain Life Science. The GenoType ${ }^{\circledR}$. MTBDRplus molecular line probe assay is divided into three procedures: (1) DNA extraction from $\mathrm{NaOH}-\mathrm{N}$-acetyl-L-cysteine-sodium citrate decontaminated smear positive specimens or from cultured isolates (solid or liquid media), (2) a multiplex polymerase chain reaction amplification, and (3) the reverse hybridization (including detection and evaluation)

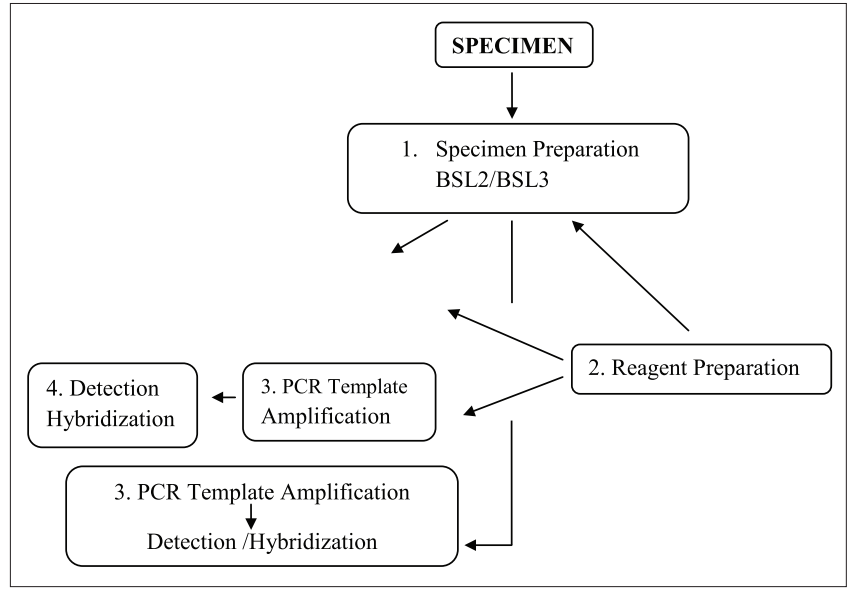

Fig. 2: An illustration of the work flow for the ideal physical design layout (4 room polymerase chain reaction [PCR] facility) and a basic (3 room PCR facility). Reagent preparation in the preamplification room must always be performed before any other procedure can be done

technologies, FIND negotiated with the manufacturing partner to obtain significant price reductions for equipment and reagents for LPA testing for the public health sector in high burden countries to facilitate widespread access to the WHO-approved technologies [46].

The MTB rpoB gene encodes the 1178 amino acid beta subunit for a DNA-dependent RNA polymerase enzyme, the mutations within an 81 base pair called "Core region" of the rроB gene are responsible for approximately $95 \%$ of the RIF resistance in MTB strains [31]. It is found that about most of the resistant strains harbor mutations in 531 codon of the rров region. As reported widely elsewhere, RIF resistance was highly associated with mutation in the 81 base pair region of the rpoB gene $[32,33]$.

The MTBDRplus assay is easy to perform and it has the capability for the rapid detection of RIF and INH-resistant MTB [34-37], the rarity of RIF-resistance-associated mutations in codons other than the rров 81-bp hot spot region and the rarity of silent mutations in the hot spot region are responsible for the high rate of detection of RIF resistance by investigation of this region [37-40]. In this study, the $\mathrm{S} 531 \mathrm{~L} / \mathrm{W}$ mutation in $r p o B$ is the most frequent 32 of 52 strains

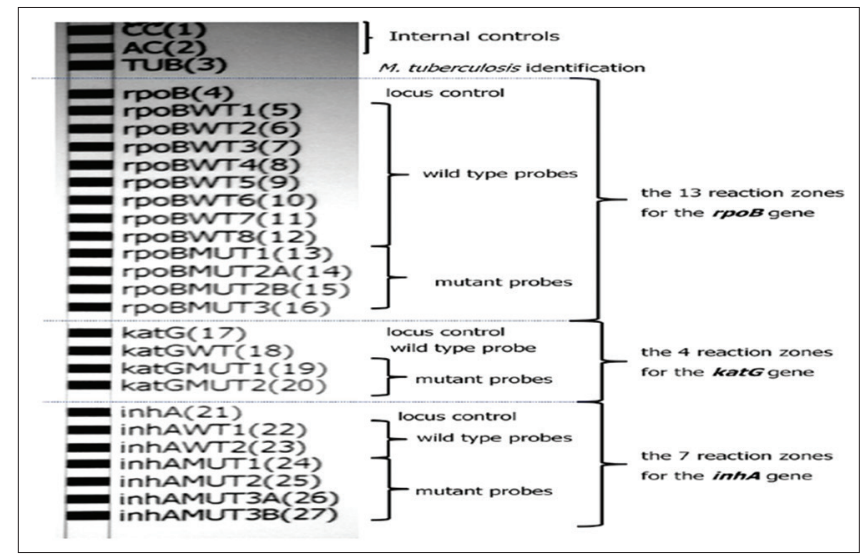

Fig. 3: (a) The bands (except CC) should be compared to the AC control band for density, (b) The TUB zone is negative, the tested bacteria does not belong to the M. tuberculosis complex and the presence or absence of any other bands (except CC and AC) cannot be considered for evaluation, (c) if the locus control zones are negative, the respective mutation-specific positive bands cannot be considered for evaluation, (d) absence of the signal with wild type probes may predict resistance, while positive hybridization

signal with a mutation-specific capture probe (for common mutations only) may predict the resistance, (e) presence of the rare mutations may only be indicated by the lack of hybridization with one or more wild type probes

(61.5\%), followed by mutations in codon 526,7 of 52 strains (13.5\%) as shown in Table 2. This is comparable to the frequencies reported in other studies [37], even though the distribution can also vary in few settings [47].

The detection of mutations in the hot spot 81-bp region of the rpoB gene was analyzed and compared with the sequence results. The confusion results such as the faint band in 531 codon WT8 or missing bands in both WT8 and MUT3 were selected and sequenced to identify the changes in amino acid sequence and nucleotide changes. When the WT8 band is weaker than that of AC and the corresponding mutation band rров MUT3 is not developed and it is considered as sensitive as shown in the Table 2 [41]. In this study, three of these mutations, yielding amino acid substitutions at positions 531 (Ser $\rightarrow$ Leu/Trp) and in 526 (His $\rightarrow$ Tyr/Asp/Arg/Leu) (Fig. 4) and also 
Table 1: Total presumptive MDR cases tested, smear positive was diagnosed by LPA and the drug susceptibility results

\begin{tabular}{lll}
\hline LPA results & Results & Percentage \\
\hline Total specimens & 8697 & - \\
Smear positive and LPA processed & 4896 & 56.3 \\
MTB detected & 4473 & 91.4 \\
RIF and INH both sensitive & 3695 & 82.6 \\
RIF and INH both resistance & 203 & 4.5 \\
RIF mono resistance & 73 & 1.6 \\
INH mono resistance & 502 & 11.2 \\
MTB not detected & 407 & 8.3 \\
Invalid & 16 & 0.3 \\
Strains show the faint band or the missing bands in WT8 and also & 52 (strains reported as sensitive) & $75 \%, 39$ strains reported as resistant) \\
missing band in specific probe MUT 3 & & \\
\hline
\end{tabular}

MDR: Multidrug-resistant, LPA: Line probe assay, MTB: Mycobacterium tuberculosis, RIF: Rifampicin, INH: Isoniazid

Table 2: 52 Strains were sequenced and the amino acid changes were observed in 39 strains, i.e., out of 52 strains 32 strains show the resistant in 531 bp region and 7 strains were resistant in 526bp region in rpoB gene with 3 strains misread

\begin{tabular}{lllll}
\hline Gene region & Mutation & Total number of resistance & Total number of sensitive & Total number of misread \\
\hline 526 & His-Tyr & 1 & Additionally amino acid changes in 7 strains were found in 526bp region \\
& His-Asp & 3 & & \\
& His-Arg & 1 & 10 & 3 \\
531 & His-leu & 2 & & 3 \\
Total & Ser-leu & 30 & 10 & 3 \\
\hline
\end{tabular}

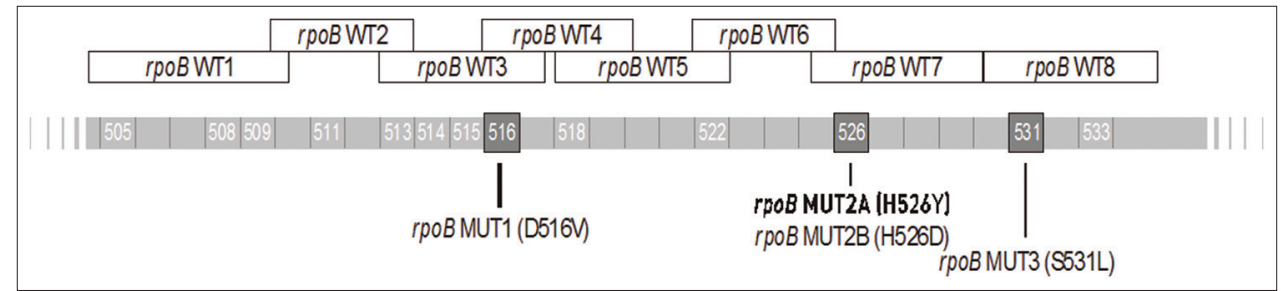

Fig. 4: rpoB mutation-specific probes: MUT D516V, H526Y, H526D, S531L and rpoB wild type probes: WT1 to WT8

it is found that, out of 52 strains reported as sensitive the sequence results show amino acid changes in 531 codon, i.e., Ser531Leu for 30 strains and Ser531Trp for 2 strains, interestingly identified that additional changes in 526 codon, i.e., His526Tyr for 1 strain, His526Asp for 3 strains, His526Arp for 1 strain, and His526Leu for 2 strain, since both mutant and wild-type bands are absent (Table 2). The Ser531Trp mutation occurs less frequently than Ser531Leu, similarly uncommon amino acid substitution that are missed by LPA also is identified at position 526 (Table 2). However these sequencing reveals that 39 of 52 isolates are resistant and LPA is shown as the faint band or absent in wild type and missing of corresponding mutation band (Fig. 4).

When the isolate is RIF resistant, it is more likely that it is also INH resistant, thus making RIF resistance a surrogate marker for the identification of MDR-TB [40]. It is also well established that isolates harboring mutations between codons 526 and 531 shows high-level resistance to RIF and that these genetic markers carry very high accuracy in RIF resistance detection [42-45]. Molecular technologies like LPA is the most promising technology to detect these mutations but the recommendation in these cases is either to control the result by DNA sequencing or confirm the result by the conventional DST.

\section{CONCLUSION}

The analysis of 52 strains which was reported as sensitive due to the confusion, i.e., the faint band or the missing band in WT8 and also missing of MUT 3 band. In this 52 strains, the amino acid changes were observed in 39 strains and it may be reported as RIF resistant and for these patients, the treatment may be provided and the transmission of the drug resistant TB also will be prevented by diagnosing these kind of samples by sequencing method rather than providing false negative report because of the confusion.

\section{ACKNOWLEDGMENTS}

We acknowledge the support provided by the State TB Officer, Director STDC/IRL, Chennai, Tamil Nadu. We would like to thank all the CTD officials and FIND INDIA officials for their support and guidance. We thank NRL, Chennai for their support in implementing and monitoring the project activities. We would like to express our appreciation to the WHO-RNTCP Consultants of Tamil Nadu. Further, we thank all patients who were enrolled in this study. We acknowledge the help of Dr. Kishore Reddy, Microbiologist, ICELT, NTI, Bangalore, Karnataka who assessing in preparing this manuscript.

\section{REFERENCES}

1. WHO: Report on Global Tuberculosis Control; 2014. Available from: http://www.who.int/tb/publications/global_report/2014/en.

2. Yew WW. Management of multidrug-resistant tuberculosis and extensively drug-resistant tuberculosis: Current status and future prospects. Kekkaku 2011;86:9-16.

3. World Health Organisation: GlobalTuberculosis Control-Epidemiology, Strategy, Financing. WHO Report, WHO/HTM/TB/2009.411. Available from: http://www. who.int/tb/publications/global report/2009/en/index. html. [Last accessed on 2009 Nov 19].

4. Jessy S, Mahmood S. Drug-resistant tuberculosis, recent approach in polymer based nanomedicine. Int J Pharm Pharm Sci 2016;8(10):1-6. 
5. World Health Organisation: Use of Liquid TB Culture and Drug Susceptibility Testing (DST) in Low-and Medium-Income Settings. Available from: http://www.who.int/tb/dots/laboratory/policy/en/ index3.html. [Last accessed on 2009 Nov 18].

6. Brossier F, Veziris N, Truffot-Pernot C, Jarlier V, Sougakoff W. Performance of the genotype MTBDR line probe assay for detection of resistance to rifampin and isoniazid in strains of Mycobacterium tuberculosis with low-and high-level resistance. J Clin Microbiol 2006;44(10):3659-64.

7. Lawn SD, Mwaba P, Bates M, Piatek A, Alexander H, Marais BJ, et al. Advances in tuberculosis diagnostics: The Xpert MTB/RIF assay and future prospects for a point-of-care test. Lancet Infect Dis 2013;13(4):349-61.

8. Cardoso RF, Cooksey RC, Morlock GP, Barco P, Cecon L, Forestiero F, et al. Screening and characterization of mutations in isoniazid-resistant Mycobacterium tuberculosis isolates obtained in Brazil. Antimicrob Agents Chemother 2004;48(9):3373-81.

9. Guo H, Seet Q, Denkin S, Parsons L, Zhang Y. Molecular characterization of isoniazid-resistant clinical isolates of Mycobacterium tuberculosis from the USA. J Med Microbiol 2006;55:1527-31.

10. Ewen KR, Bahlo M, Treloar SA, Levinson DF, Mowry B, Barlow JW, et al. Identification and analysis of error types in high-throughput genotyping. Am J Hum Genet 2000;67(3):727-36.

11. Garcia L, Alonso-Sanz M, Rebollo MJ, Tercero JC, Chaves F. Mutations in the rpoB gene of rifampin-resistant Mycobacterium tuberculosis isolates in Spain and their rapid detection by PCR-enzyme-linked immunosorbent assay. J Clin Microbiol 2001;39(5):1813-8

12. Van Der Zanden AG, Te Koppele-Vije EM, Vijaya Bhanu N, Van Soolingen D, Schouls LM. Use of DNA extracts from ZiehlNeelsen-stained slides for molecular detection of rifampin resistance and spoligotyping of Mycobacterium tuberculosis. J Clin Microbiol 2003;41(3):1101-8.

13. Heep M, Brandstätter B, Rieger U, Lehn N, Richter E, Rüsch-Gerdes S, et al. Frequency of rpoB mutations inside and outside the cluster I region in rifampin-resistant clinical Mycobacterium tuberculosis isolates. J Clin Microbiol 2001;39(1):107-10.

14. Ahmad S, Mokaddas E, Fares E. Characterization of rpo B mutations in rifampin-resistant clinical Mycobacterium tuberculosis isolates from Kuwait and Dubai. Diagn Microbiol Infect Dis 2002;44(3):245-52.

15. Mani C, Selvakumar N, Narayanan S, Narayanan PR. Mutations in the rpoB gene of multidrug-resistant Mycobacterium tuberculosis clinical isolates from India. J Clin Microbiol 2001;39(8):2987-90

16. Boehme CC, Nicol MP, Nabeta P, Michael JS, Gotuzzo E, Tahirli R, et al. Feasibility, diagnostic accuracy, and effectiveness of decentralised use of the Xpert MTB/RIF test for diagnosis of tuberculosis and multidrug resistance: A multicentre implementation study. Lancet 2011;377(9776):1495-505.

17. Mäkinen J, Marttila HJ, Marjamaki M, Viljanen MK, Soini H. Comparison of two commercially available DNA line probe assays for detection of multidrug-resistant Mycobacterium tuberculosis. J Clin Microbiol 2006;44(2):350-2.

18. World Health Organisation. Policy Statement. Molecular Line Probe Assays for Rapid Screening of patients at Risk of Multidrug Resistant Tuberculosis (MDR-TB). Geneva: WHO; 2008.

19. Genotype MTBDRplus ${ }^{\mathrm{TM}}$, Version 1.0. Nehren, Germany: Hain Lifescience GmbH. Available from: http://www.hainlifescience.com/ pdf/304xx_pbl.pdf.

20. Ling DI, Zwerling AA, Pai M. Genotype MTBDR assays for the diagnosis of multidrug-resistant tuberculosis: A meta-analysis. Eur Respir J 2008;32(5):1165-74

21. Kumar P, Balooni V, Sharma BK, Kapil V, Sachdeva KS, Singh S. High degree of multi-drug resistance and hetero-resistance in pulmonary TB patients from Punjab state of India. Tuberculosis (Edinb) 2014;94(1):73-80

22. Bhalla M, Sidiqi Z, Sharma PP, Singhal R, Myneedu VP, Sarin R. Performance of light-emitting diode Fluorescence microscope for diagnosis of tuberculosis. Int J Mycobacteriol 2013;2(3):174-8.

23. Barnard M, Somoskovi A. Molecular detection of drug-resistant tuberculosis by line probe assay. Laboratory Manual. Vol. 22. New York: Academic Press; 2012. p. 65-104.

24. Kent PT, Kubica GP. Public Health Mycobacteriology: A Guide for a Level III Laboratory. Atlanta, GA: Centers for Disease Control and Prevention; 1985.

25. Hain Lifescience GmbH. Genotype MTBDRplus, Version 2.0. Nehren, Germany. Available from: http://www.hain-lifescience.de/en/ instructions-for-use.html

26. World Health Organization. Molecular Line Probe Assay for Rapid Screening of Patients at Risk of Multidrug-Resistant Tuberculosis (MDRTB). Geneva, Switzerland: World Health Organization; 2008. Available from: http://www.who.int/tb/features_archive/policy_ statement.pdf.

27. Anek-Vorapong R, Sinthuwattanawibool C, Podewils LJ, McCarthy K, Ngamlert K, Promsarin B, et al. Validation of the genotype MTBDRplus assay for detection of MDR-TB in a public health laboratory in Thailand. BMC Infect Dis 2010;10:123.

28. Daum LT, Rodriguez JD, Worthy SA, Ismail NA, Omar SV, Dreyer AW, et al. Next-generation ion torrent sequencing of drug resistance mutations in Mycobacterium tuberculosis strains. J Clin Microbiol 2012;50(12):3831-7.

29. Kurniawat F, Sulaiman SA, Gillani SW. Study on drug-resistant tuberculosis and tuberculosis treatment on patients with drug resistant tuberculosis in chest clinic outpatient department. Int J Pharm Pharm Sci 2012;4(2):733-7.

30. Behr MA, Warren SA, Salamon H, Hopewell PC, Ponce de Leon A, Daley CL, et al. Transmission of Mycobacterium tuberculosis from patients smear-negative for acid-fast bacilli. Lancet 1999;353(9151):444-9.

31. Telenti A, Imboden P, Marchesi F, Lowrie D, Cole S, Colston MJ, et al. Detection of rifampicin-resistance mutations in Mycobacterium tuberculosis. Lancet 1993;341(8846):647-50.

32. Mohammed SH, et al. First experience with using simple polymerase chain reaction-based methods as an alternative to phenotypic drug susceptibility testing for Myobacterium tuberculosis in Iraq. Int. J. Appl Basic Med Res 2013;3(2):98-105.

33. Van Rie A, Warren R, Mshanga I, Jordaan A, van der Spuy GD, Richardson $\mathrm{M}$, et al. Analysis for a limited number of gene codons can predict drug resistance of Mycobacterium tuberculosis in a highincidence community. J Clin Microbiol 2001;39(2):636-41.

34. Bang D, Bengård Andersen $\mathrm{A}$, Thomsen VØ. Rapid genotypic detection of rifampin-and isoniazid-resistant Mycobacterium tuberculosis directly in clinical specimens. J Clin Microbiol 2006;44(7):2605-8.

35. Hillemann D, Rüsch-Gerdes S, Richter E. Application of the genotype MTBDR assay directly on sputum specimens. Int J Tuberc Lung Dis 2006;10(9):1057-9.

36. Marzouk M, et al., Evaluation of Genotype ${ }^{\circledR}$ MTBDRplus assay for rapid detection of resistance to isoniazid and rifampin in mycobacterium tuberculosis isolates collected in Tunisia, J Mycobac Dis 2014;4(2): $1-3$.

37. Miotto P, Piana F, Penati V, Canducci F, Migliori GB, Cirillo DM. Use of genotype MTBDR assay for molecular detection of rifampin and isoniazid resistance in Mycobacterium tuberculosis clinical strains isolated in Italy. J Clin Microbiol 2006;44(7):2485-91.

38. Sajduda A, et al., Molecular characterization of rifampin- and isoniazidresistant mycobacterium tuberculosis strains isolated in Poland, J Clin Microbiol. 2004:42(6):2425-31.

39. Hillemann D, Weizenegger M, Kubica T, Richter E, Niemann S. Use of the genotype MTBDR assay for rapid detection of rifampin and isoniazid resistance in Mycobacterium tuberculosis complex isolates. J Clin Microbiol 2005;43(8):3699-703.

40. Hillemann D, Kubica T, Rüsch-Gerdes S, Niemann S. Disequilibrium in distribution of resistance mutations among Beijing and non-Beijing Mycobacterium tuberculosis strains isolated from patients resident in Germany. Antimicrob Agents Chemother 2005;49(3):1229-31.

41. Hillemann D, et al., Use of the Genotype MTBDR Assay for rapid detection of rifampin and isoniazid resistance in mycobacterium tuberculosis complex isolates. J Clin Microbiol 2005;33(8):3699-703

42. Somoskovi A, Parsons LM, Salfinger M. The molecular basis of resistance to isoniazid, rifampin, and pyrazinamide in Mycobacterium tuberculosis. Respir Res 2001;2(3):164-8.

43. Comparison of Xpert MTB/RIF with line probe assay for detection of Rifampin-Monoresistant Mycobacterium tuberculosis, J Clin Microbiol, 2014:52(6):846-1852.

44. Williams DL, Spring L, Collins L, Miller LP, Heifets LB, Gangadharam PR, et al. Contribution of rpoB mutations to development of rifamycin cross-resistance in Mycobacterium tuberculosis. Antimicrob Agents Chemother 1998;42(7):1853-7.

45. Yang B, Koga H, Ohno H, Ogawa K, Fukuda M, Hirakata Y, et al. Relationship between antimycobacterial activities of rifampicin, rifabutin and KRM-1648 and rpoB mutations of Mycobacterium tuberculosis. J Antimicrob Chemother 1998;42(5):621-8. 
46. Foundation for Innovative New Diagnostics: FIND Prices for Genotype ${ }^{\circledR}$ MTBDRplus and Country List. Available from: http:// www.finddiagnostics.org/programs/find-negotiated-prices/mtbdrplus. html. [Last accessed on 2010 Feb 02].
47. Bártfai Z, Somoskövi A, Ködmön C, Szabó N, Puskás E, Kosztolányi L, et al. Molecularcharacterization of rifampin-resistant isolates of Mycobacterium tuberculosis from Hungary by DNA sequencing and the line probe assay. J Clin Microbiol 2001;39(10):3736-9. 